\title{
Developing and Renovating Hospitality Properties
}

\author{
Jack B. Corgel, Jan A. deRoos, and Kevin Fitzpatrick
}

Land development includes acquisition of land, securing zoning changes from local governments, installation of infrastructure improvements to land such as streets and utilities, and constructing buildings to generate revenue. In this chapter, we discuss those processes as they relate to developing hospitality properties-a process far more complex than that associated with other commercial real estate.

\section{Formation of Development Teams}

From a business perspective, developers function both as entrepreneurs, who commit time and money for uncertain returns, and managers, who assemble and administer the resources necessary to ensure project success. Figure 20.1 shows various business relationships involving a developer and others. These relationships fall into two categories: those who supply services, materials, and labor directly toward the creation of the physical real estate, and those who supply financial capital.

Suppliers of Financial Capital

Development and construction projects, like companies, have a financial capital structure usually comprising debt and equity. Chapters 17 and 19 presented some of the structures of equity investment that help finance real estate, including development projects. One form not mentioned earlier is joint-venture arrangements structured as partnerships. In equity joint ventures, money partners supply most of the funds necessary to advance projects, while developers mainly supply ideas and the managerial skills to complete the projects. 
Figure 20.1

Development Team Relationships

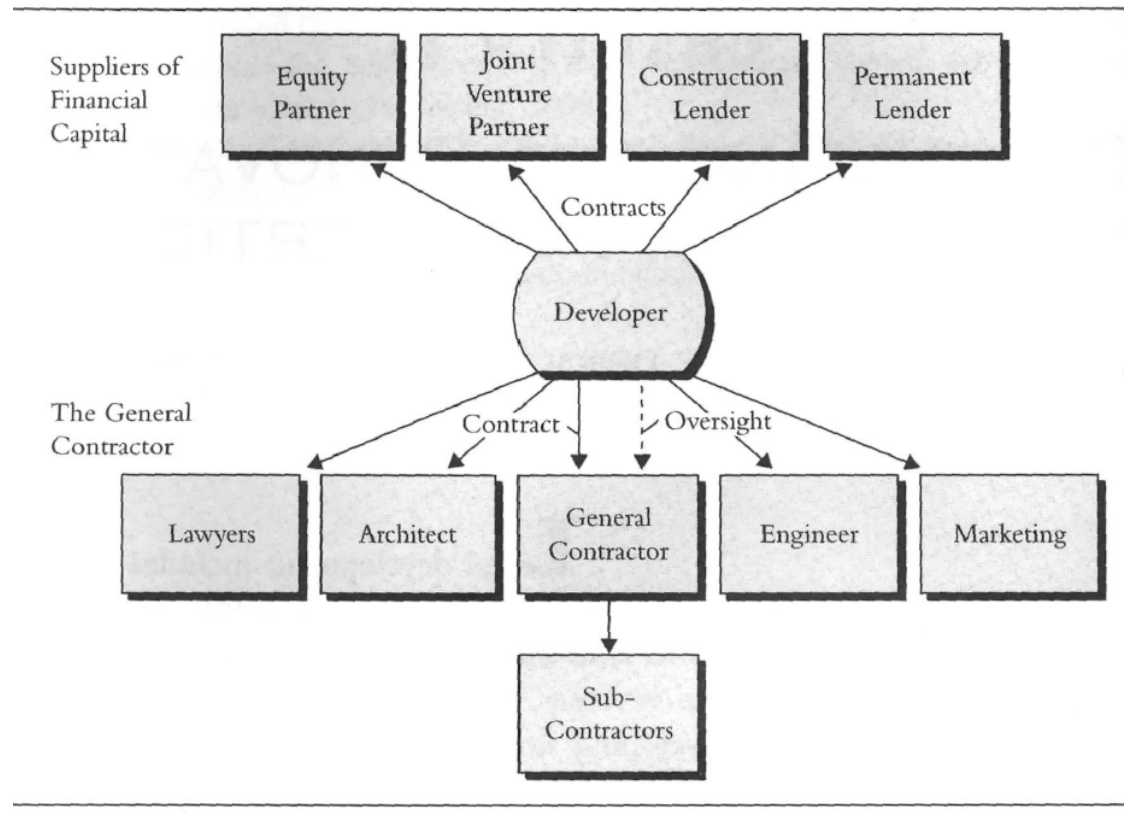

The Development Process

Regardless of the ownership structure, the economic viability of a project will depend on several factors, beginning with your goals. The development process is shown in Figure 20.2. As you look at a particular site to determine the highest and best use for that site, you might consider numerous possible investments including hospitality, residential, commercial, or possibly a mixed-use development. An important component of that analysis will include such matters as current zoning and the local planning department's desires for the site, as well as access and proximity to demand generators. One possibility is that you have a mixed-use site that requires a hospitality component due to zoning or as a valueadded element to the overall development.

Regardless of the reason, if you are determining the feasibility of a new hotel, you must consider existing and proposed competition, the demand drivers for the product, the seasonality of the business, and any business segments not being served by existing hotels (e.g., corporate traveler, meeting and groups, or leisure travelers). When reviewing the viability of a local hotel, it is critical that you understand the local hotel room demand generators. If a portion of your business is generated by a local business or tourist attraction, it is important to check the economic viability of that demand generator, including its ability to change location. Niagara Falls isn't going anywhere, but a tenant in a multiuse development can easily relocate. You can start by meeting with managers of existing hotels to 
determine the level of business, and with government officials to determine what revenue information the local hotels file that is part of the public record, including tax assessments.

Figure 20.2

Stages in the Development Process

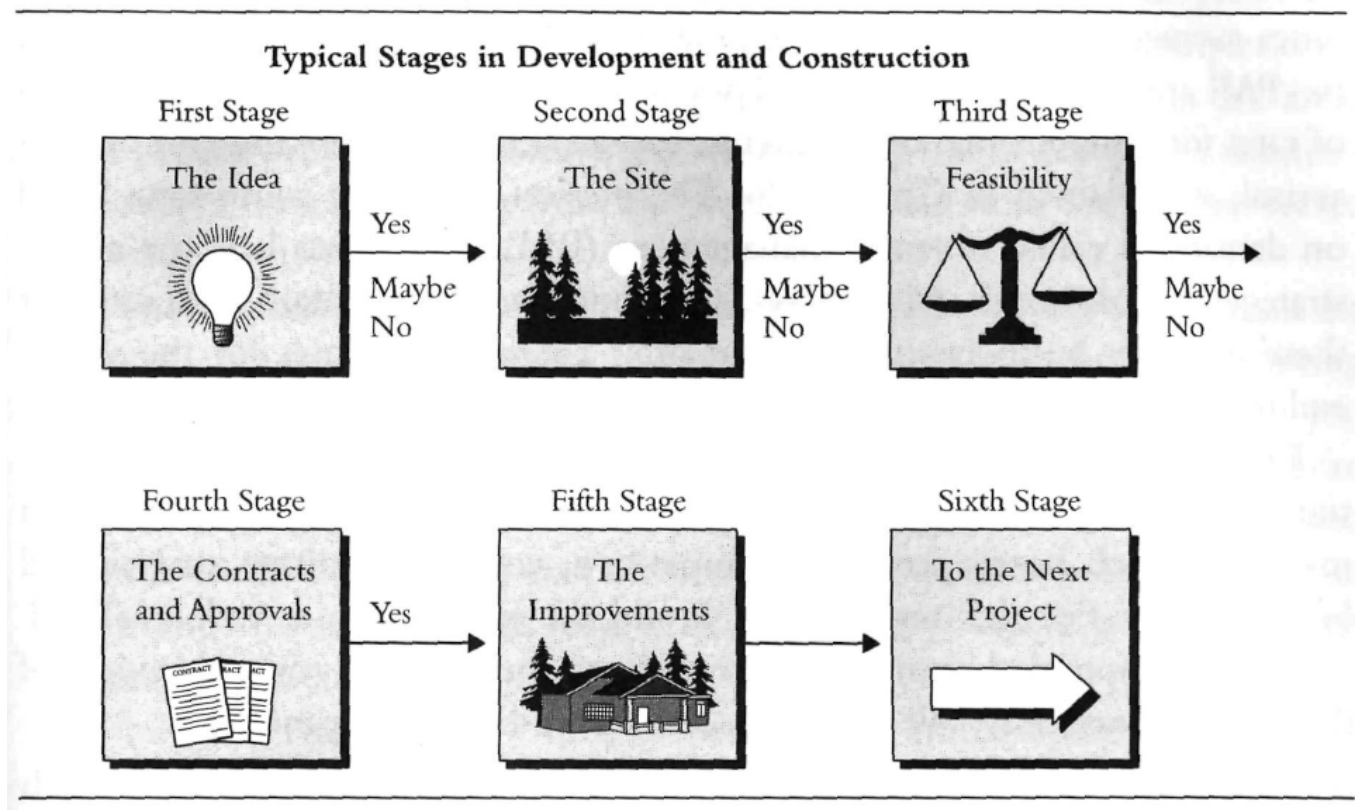

Given the benefits that hotels provide to the local community (including jobs and tax revenues), you should contact local government leaders to determine all forms of support that they can provide for your proposed development, including improvements to access and utilities, tax credits for training and real estate tax abatements, and financing guarantees. The amount of support for a particular hotel can vary greatly from one location to another.

Determining occupancy rates is critical for your financial pro forma. Hotels that cater to business travelers are often busy during the week but suffer on weekends. Such hotels appear to be successful because they operate at or near capacity for four nights per week, but they face low occupancy for the three weekend nights. That pattern does not maximize the use of the property. So you need to determine what other market segments your hotel might serve, to ease this peak and valley occupancy. The most successful hotels are those that have a business mix, which allows them to successfully maximize revenue from a number of market segments. Low-rate business in slow periods adds revenue when demand for high-rate business does not exist. The best measure of revenue is revenue per available room (RevPAR), which combines average daily rate (ADR) with average occupancy. Hotels with a high RevPAR are generally successful. They usually do this by offering a portfolio of rates for different market segments, based on time of booking and time of arrival, as explained in Chapter 26. The process 
of setting room rates based on demand is called revenue management (RM), which has become a core strategy of most hotels. Most likely, your hotel would maintain high rates for those weekday business travelers, but offer promotional rates for the weekend traffic.

Early in the process, you must determine which hotels are truly competition for the product you intend to build. This is your competitive set. If you misjudge which hotels are truly competitive, your competitive analysis will be inaccurate. For this reason, you would do well to hire a well-qualified, independent appraisal company to complete a market analysis and review of the project's feasibility. We discuss feasibility studies in a moment.

If the site review is favorable and you have identified a product concept, you need to consider your brand positioning. You can choose among a major chain brand, a small chain brand, or an independent operation. As discussed in Chapter 17, part of this decision involves assessing who will manage the property. You can retain a manager and manage it yourself, contract with an independent management company, or contract with the branded management firm. If you want a franchise brand, you must obtain a franchise and execute a separate management agreement with a hotel management company. As discussed in Chapter 19, franchise agreements allow you to use the brand's name, trade dress, reservation systems, and management techniques. You must operate the hotel according to the franchisor's brand standards or lose the right to use the brand. Even if you manage the hotel yourself, for legal and tax purposes you would normally create a separate management company and execute a management agreement between your ownership group and your management company.

One place to look when you are evaluating brands is the major brand's Web sites. Hotel companies' Web sites usually define the products they offer, the markets their products are designed for, and the process you'd follow to obtain approval for a franchise and to build a property. Many hotel company development Web sites will give you such specific requirements as room size, room mix, total building gross area, and even parking. It is important to recognize that these design details are for prototypes only and the ultimate design characteristics need to be refined for the site in question. The hotel company will help you analyze whether and how one of their products may be successful for your site. Some brands won't be available due to prior commitments, but most hotel companies can recommend a particular prototype and provide general cost estimates for construction and project completion.

As you evaluate brands, consider competing brand products in the area, guest loyalty programs, franchise fees, your management company's familiarity with the brand, support from the franchisor, and how the product serves the needs of the market. 
If you're planning to purchase an existing hotel, you have a different set of considerations. First, you must determine whether to keep the existing brand or to rebrand the hotel. Your decision may be driven by whether you are buying a successful hotel or one that has been struggling. Rebranding can be a difficult task since you will have to address cancellation rights and costs with the current brand, the cost of modifying the current hotel to meet your new brand's design standards, and what hotels will compete with your newly branded hotel.

While you could retain a firm to perform the initial concept review, it is important that you be knowledgeable and comfortable with the market environment since your money is at risk. In addition, the work of this initial due diligence phase is virtually worthless if the project does not move forward. Costs incurred for projects that are not built are called dead deal costs, while costs incurred for projects that are built are included as a project cost. Successful developers make it a point of keeping dead deal costs to a minimum.

Feasibility Study

Once you are comfortable with your market investigation, the next step is to commission a feasibility study. The consultant can either evaluate a particular product for your site or work with you to identify the best prototype for the site. To formulate their recommendation, the feasibility company will use such inputs as interviews with area hotel managers and government officials, local demand generators, and market information gained from other work they have done in the area. When selecting a hotel consultant, seek out one that has extensive hospitality knowledge as well as knowledge of the planned prototype. In addition, the consultant should have access to several years of industry data for your market (usually, STAR reports from Smith Travel Research). The feasibility study will examine the project, the market, and competitors; expected mix of corporate, individual, and leisure travelers; average rate and occupancy; and departmental revenues and expenses, overhead expenses, and reserves. It will also forecast the first five or 10 years of the property's expected financial performance. Since the consultant does not know the capital structure, feasibility projections may not include debt service coverage or return to the owner. That said, you may want to leave the capital structure out of the report, as you consider alternative financing structures.

Often, the consultant also will indicate the value of the hotel. Hotels need time to become fully operational, gain full market recognition and acceptance, and become stabilized in terms of revenue. The feasibility study can provide a value at completion and a value at stabilization. It is important that the stabilized value be higher than the cost of construction, or there's no point in proceeding. This 
spread between cost and value is known as the developer profit, which is your compensation for the risk and expense of building a hotel. You determine the amount of development profit that is "adequate," based on the reason for the hotel's construction. For example, if the hotel is part of a mixed-use project, the contribution the hotel component adds to the overall complex should be taken into consideration.

\section{Financing Review}

Feasibility study in hand, you go to a lender or finance broker to determine the amount of construction debt and permanent financing available for the project. The result will be an indicative term sheet that identifies the loan amount, rate, security for the loan, basic loan covenants, and repayment terms. From this, you can summarize the full cost of construction on a spreadsheet, using the information provided by the consultant together with the information prepared by the loan broker or lender. Your estimate will include debt service, the amount of equity required, return to your equity, and your ultimate profit. Make note of any guarantees the lenders are requiring, and realize that the proposed terms are only initial terms that may vary substantially prior to closing the loan. There is still some time before you will be prepared to submit a loan package to the lender, and changes in the market environment will affect the capital package of debt and equity. In the interim, you might see changes in interest rate, the economic situation, and the lender's appetite for real estate loans and hotel loans in particular.

You'll probably be involved with two loans, one for construction and the other for permanent financing. Construction financing can include assistance with land assemblage and includes all construction costs. It extends for a period after opening to allow the property to stabilize. The construction lender is often a commercial bank, which may require that the owner's equity be funded first and require personal guarantees along with other requirements to ensure repayment of the loan. The interest rate for construction financing is generally a floating, or adjustable rate, which changes according to an index such as the prime rate. Once your property is stabilized, permanent lenders provide financing based on the property's performance. The level of debt is determined by many factors including the loan-to-value ratio (i.e., loan amount divided by the property value), the debt service coverage rate (annual property cash flow available for debt service divided by the annual debt service), the operating history of the property, and the management company's expertise. The interest rate for permanent financing is generally fixed for the term of the loan, and often the security for the loan is limited to the hotel. Any personal liability you might have is restricted to representations made to the 
lender. An experienced mortgage broker familiar with market terms and the requirements of particular lenders can be a great asset to canvass the market for available lenders.

\section{Overall Program}

The mix of guest rooms, meeting space, back-of-house space, and food and beverage space is called the program, which is covered in detail in Chapter 21. The program will have a large hand in driving the hotel's design. It is critical to assemble a team of experienced professionals who can properly allocate space within the property so the hotel can both operate efficiently and provide an appropriate level of guest satisfaction. The design team must include professionals capable of determining the project's impact on adjoining sites, including traffic, noise, and water runoff. The team members must also know how to evaluate different design elements to make the property cost effective from an energy standpoint and evaluate whether the property will meet the Leadership in Energy and Environmental Design (LEED) standards established by the United States Green Building Council.

\section{Economic Feasibility of a Select Service Hotel}

In this chapter, we examined how you as a hotel developer evaluate projects to determine whether they will receive their desired returns. Let's look at how this works out in a real-world situation, with the investment possibility in Grandville, USA, for Alexandra Brown and her firm, Big Red Development (BRD).

\section{The Investment and Financing Decision}

BRD has submitted a loan application for the project to the Local Commercial Bank (LCB), based on the following summary data: BRD's development department has estimated the cost to develop as $\$ 21$ million.

The construction costs have been verified by a general contractor, and the furniture, fixtures, and equipment (FF\&E) costs are based on a similar hotel that opened recently. The bank's appraiser prepared a forecast of hotel operations, and used that to generate an estimate of market value of $\$ 22.5$ million. The full investment analysis assumptions are shown in Figure 20.3. Brown feels that the Grandville economy is much stronger than indicated in the appraiser's market study and opinion of market value. She has performed extensive market research to forecast occupancy and average rates, and has worked closely with her operations 
team to create a realistic set of financial projections using results from the three companyoperated properties as benchmarks. Based on this research, she is convinced that property performance will be stronger than the bank's appraisal pro forma indicates. However, LCB insists on using the appraisal report's estimate of market value in their evaluation. The bank's conservative approach is evident in the size of the loan they are willing to extend, which is 67 percent of the costs of development, not 67 percent of the appraised value. This means that BRD must invest $\$ 7$ million of equity (33 percent of the project cost).

Last week, Brown submitted her LCB loan application. LCB responded favorably, indicating that the project would be considered for a loan given the success of BRD's two recently completed projects. The senior loan officer provided a term sheet with the following loan terms:

\begin{tabular}{ll}
\hline Development Cost & $\$ 21$ million \\
Loan Size & $\$ 14$ million \\
Interest Rate on Mortgage & 7.5 percent \\
Amortization Term & 25 -year term, monthly payments \\
\hline
\end{tabular}

BRD has a long relationship with LCB and feels that continuing to shop the loan would not be productive. To support the investment decision, Brown must calculate the returns on the investment, using the current loan terms from LCB. For this purpose, she will need to answer two key questions:

- Is the net present value (NPV) of the overall investment decision, not considering borrowing, positive? If yes, the project is economically viable.

- Is the NPV of the equity investment decision (after deducting borrowing costs) positive? This will be considered both before and after the impact of income taxes. If the NPV is positive, this indicates that the decision to invest equity is supported.

Brown performs an analysis that assumes a 12-year holding period, 2 years preopening, and 10 years of operation. She estimates the selling price of the hotel at the end of the 10-year operating period and performs a discounted cash flow analysis to provide an estimate of holding period NPV and the yields (internal rate of return, or IRR). The firm feels that Select Service Hotels should provide a minimum 11 percent overall yield. The firm has a minimum equity return requirement of 16 percent on a before-tax basis and 13 percent on an after-tax basis. Based on Brown's analysis, the project's numbers are as follows: 


\begin{tabular}{lcccc}
\hline & Cost & Value & NPV & IRR \\
\hline Overall Project & $\$ 21.0$ million & \$23.6 million & \$2.6 million & $12.79 \%$ \\
Equity - before Tax & $\$ 7.0$ million & $\$ 8.66$ million & $\$ 1.66$ million & $19.27 \%$ \\
Equity - after Tax & $\$ 7.0$ million & $\$ 8.51$ million & $\$ 1.51$ million & $15.85 \%$ \\
\hline
\end{tabular}

Every indicator points to a positive investment decision; the values are greater than the cost, the NPV is positive, and the IRR is above the required rate of return in every case. In addition, the project is eligible for two tax incentive programs; the first is a 50 percent rebate of real estate taxes in the first five years of operation to offset offsite improvements made to develop the hotel; the second is an employee job training tax credit of $\$ 350$ per employee. The combined value of these programs adds $\$ 1$ million to the project and equity NPV. Thus, Brown thinks the project is worth approximately $\$ 24.6$ million when it is developed. For these reasons, the project is a go, and the Grandville Select Service Hotel will be constructed.

\section{Figure 20.3 Investment Analysis}

Select Service Hotel, Research Triangle Area, USA

Investment Analysis Assumptions - Select Service Hotel

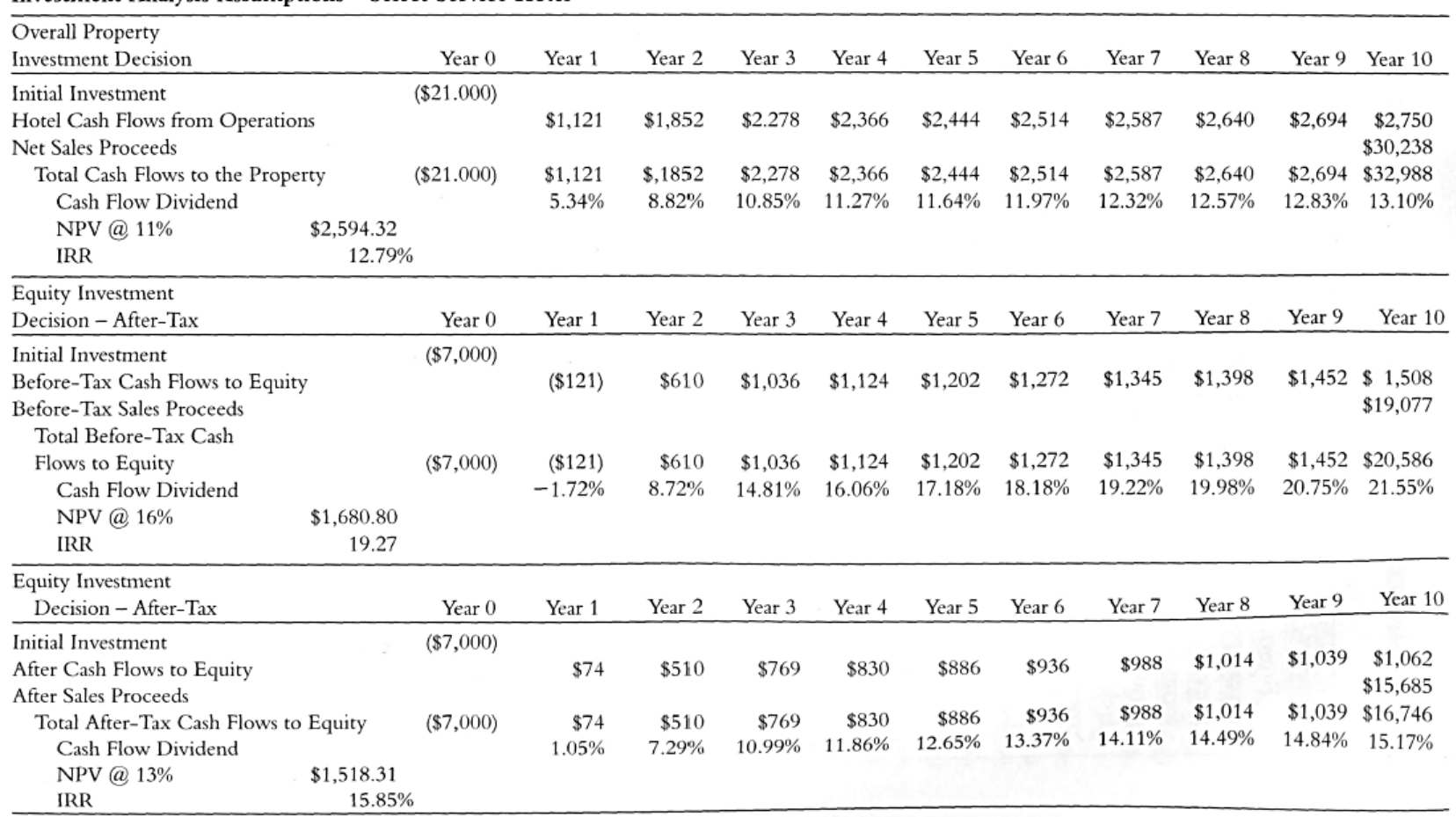




\section{Construction and Property Opening}

Chapter 17 urged you to seek legal counsel in structuring your ownership, and you received similar advice in Chapter 19, regarding contracts and leases. Again, the importance of a sound legal team cannot be underestimated. The legal team must not only be able to help with purchasing land to assemble the site and with construction, but they must also be able to assist with the negotiations with the franchisor and management company. Coordination of the contracts among varying parties early on is critical to the ease of operation and will hopefully prevent subsequent costly conflicts.

You'll also need an experienced and diligent architectural team. This team not only needs experience with hotels generally, but also with the specific type of hotel that you're building. For franchise hotels, it is important that the architects be comfortable with working in a situation where they must conform to brand standards, leaving little room for creativity. At the same time, no two sites are the same and the plans must be adjusted to local conditions and local construction codes. The architect will retain a mechanical and electrical engineer, a structural engineer, a soils engineer, local code compliance experts, and a traffic engineer, if needed. In addition, you will likely need to retain an environmental engineer that conducts the preliminary site environmental review.

Construction contracts take one of three forms. In a fixed-price or lump-sum arrangement the contractor will build the project for a fixed price; in a guaranteed-maximum-price contract, the contractor agrees to a maximum price for construction and you and the contractor share any savings below that maximum price; and in a construction-management contract the contractor takes bids from various subcontractors, but you are at risk for the ultimate price. Even if the contract is a maximumprice contract or a stipulated-sum contract, you remain liable for any unforeseen site conditions.

As work proceeds, the contractor will issue monthly requests for payment, which you, the construction consultant, architect, and construction lender all review. If there are change orders, you must obtain quick pricing for any such changes. The construction lender will generally require the owner to ensure the work is hen free, which means the contractors must be paid. In addition, the construction loan must be kept in balance so that costs of completion are covered by equity and the construction loan. Any cost increases due to change orders or delayed construction must be funded by additional equity if reserves are insufficient.

Before you even start construction, you must secure financing, obtain all construction approvals, and have a franchise approval, if applicable. Further, it is critical for you to fully understand the local requirements for property inspection during construction, and to receive a certificate of occupancy to 
open the hotel. This information must be coordinated with the requirements of the construction lender and the franchisor.

Construction costs are often divided into land, hard costs, soft costs, FF\&E, and preopening and working capital. A contingency for unexpected items can be added as a separate category or included in each subcategory. Land includes the actual cost of the land and cost related to the acquisition. Hard costs are the actual costs of constructing the building, for example, the construction contract. Soft costs include all consultants and advisors, including the architect, legal, accounting, brokerage, and franchise fees, and testing during construction. The FF\&E outfit your hotel for operation. Preopening and working capital are the costs of retaining staff and training personnel and marketing prior to opening, money for the hotel to acquire food and beverages prior to opening, and the estimated initial losses until the hotel achieves breakeven.

Property Opening A hotel opening is a complex matter, since the hotel itself must be ready to open, and you also need to retain staff, market the property, and train the staff prior to opening. Often, the first person retained for a new hotel is the marketing manager, who conducts detailed due diligence on potential clients and establishes a presence in the market. You or your management firm will hire the general manager and other department heads months prior to the hotel's opening. Among other things, this permits them to resign from their current assignment and relocate their families if necessary.

The senior staff will begin to review training and operating manuals prepared by the franchisor or the management company, and adjust them for the needs of the particular property. Staff selection is critical to the success of the property, and managers often work with outside consultants to attract a large pool of potential applicants and select those best suited for the property. Based on the construction completion date, the management team will schedule training periods and begin to take over portions of the property to allow the employees access to the work areas, begin to train in the actual space, stock the work rooms, and operate the kitchen equipment.

The manager will increase the number of employees on the payroll as the opening date approaches. In addition, the sales team will be booking business anticipating the hotel opening (preopening sales). Any delay in construction can be costly at this point, since not only are you paying additional construction interest, but you are also paying for the preopening staff along with potential costs for relocating business that was booked into the hotel. The actual hotel opening requires the approval of the local authorities, including the building department and the fire department, as well as the hotel franchisor, and the management company (if there is one). This period can be stressful especially if the team is not familiar with the process. 
For properties that operate in a seasonal business, it is critical that you select a competent contractor that can complete the property on time and not miss the high-rate seasonal business. Many professional meeting planners will not book your hotel until it is actually open to ensure the meeting can be accommodated and the staff is properly trained.

If you successfully make your way through this process, congratulations. Your hotel will probably open quietly (soft opening) to get operations going until the grand or hard opening. From this point, you and your managers will be focusing on the information found in later chapters, such as building your brand, setting appropriate prices through revenue management, and addressing market segmentation. 